AperTO - Archivio Istituzionale Open Access dell'Università di Torino

\title{
Persistency in the NEET state: a longitudinal analysis
}

\section{This is the author's manuscript}

Original Citation:

Availability:

This version is available http://hdl.handle.net/2318/1690470

since 2021-03-12T08:36:42Z

Published version:

DOI:10.1080/13676261.2018.1562161

Terms of use:

Open Access

Anyone can freely access the full text of works made available as "Open Access". Works made available under a Creative Commons license can be used according to the terms and conditions of said license. Use of all other works requires consent of the right holder (author or publisher) if not exempted from copyright protection by the applicable law. 


\title{
Persistency in the NEET state. A longitudinal analysis
}

\author{
Dalit Contini $^{\mathrm{a}}$, Marianna Filandri ${ }^{\mathrm{b}}$ and Lia Pacelli ${ }^{\mathrm{a}}$ \\ a'Department of Economics and Statistics 'Cognetti de Martiis', University of Torino, Torino, Italy; \\ ${ }^{\mathrm{b}}$ Department of Cultures, Politics, and Society, University of Torino, Torino, Italy
}

\section{Introduction}

The integration of young people into society has been traditionally depicted as a sequence of steps from school to work. However, this regular path is no longer representative of the youth's life course (Eurofound, 2012). Due to the general surge of non-standard and temporary job contracts, paralleled by increasing youth unemployment rates in many countries in the aftermath of the economic crisis, contemporary young people tend to experience diversified paths into adulthood, irregular educational careers, delayed entrance in the labour market and intermittent working careers.

In these changing societies, the term NEET has been coined to identify young individuals not engaged in education, employment or training, with the aim to expand the focus from youth unemployment to include those who have given up looking for work or who are detached from the labour market. Differently from the unemployment rate, defined as the share of unemployed over the individuals actively involved in the labour market (by either working or looking for work), the NEET rate measures the share of NEET over the entire population in the same age band. Thus, it measures the proportion of young persons who are not working or studying, regardless of whether their condition is voluntary or involuntary, and what they actually do to leave it.

The NEET rate is being increasingly used in developed economies as a measure of youth marginalization (UCW, 2013). The term NEET first appeared in the nineties to characterize teenager school dropouts who were not studying nor working, and was later expanded to include young individuals in their twenties. Because they are neither improving their future employability through investment in skills via schooling or training nor gaining experience through employment, NEETs are considered as being particularly at risk of both labour market and social exclusion. The prevalence of NEET has increased in most European countries in the years after the great recession, but is extremely variable across countries, 
between 5\% in the Netherlands to over 21\% in Italy (data for year 2015, age 15-24, Eurofund, 2016).

To our knowledge, the NEET phenomenon has been investigated only with cross sectional data (e.g. Bynner \& Parsons, 2002; Furlong, 2006; Williamson, 2010). Yet, a given crosssectional share of NEET may coexist with a large group of young people experiencing the condition for a limited amount of time, or a smaller share of persistently NEET. In this perspective, a better understanding of how long different individuals remain in the state would be highly relevant to design appropriate policy interventions (Roberts, 2011; Serrano Pascual \& Martín Martín, 2017).

Our paper aims at overcoming this limitation, by analysing the NEET phenomenon in a longitudinal perspective. We examine the case of Italy, a country experiencing one of the highest and increasing NEET shares in the EU. We analyse the Italian longitudinal sample of the EU-SILC data, providing self-declared information on individuals' educational and labour market status on a monthly basis for 4 years. Focusing on the period 2008-2014 (waves 20082011), we analyse the condition over time of young adults whose age at the first interview ranges between 19 - when regular students complete upper secondary education - and 29. During this period, respondents might be still engaged in formal education (either tertiary education or delayed secondary school attendance), training activities, or facing entrance into the labour market.

More specifically, we will address three research questions:

i) Is NEET a transient or persistent condition? We propose a longitudinal classification of individual careers across the employment, in education or training and NEET states, and provide a picture of the relative size of short and long-term-NEET groups at the national level.

ii) Who are the long-term NEETs? Who are those more at risk of becoming long-term NEETs? We examine the composition of NEET groups in terms of socio-demographic characteristics and deliver a long-term NEET risk profile.

iii) How are long-term-NEET individual careers characterised in terms of unemployment or inactivity? Distinguishing between unemployment and inactivity is essential to provide meaningful policy recommendations. As we will see, the large majority of the individuals experiencing a long-term NEET condition portray themselves as unemployed. Reflecting the well-known low labour market participation rate of Italian females, the only notable exception is women with children, a substantial share of which declares to be inactive for most of the time. 


\section{The debate around the NEET concept}

Young people not in education, employment or training are an issue of growing concern in many countries and have been the subject of a broad range of policy interventions. The NEET concept has spread out since the late nineties and has helped to raise the attention on different patterns of vulnerability at a time when youth unemployment rates were declining. Due to its increasing use in the media and in public discourse, the NEET term is now well known to a wide audience, and considered a useful indicator for monitoring the labour market and social condition of young individuals. However, in the scientific community there is a lively debate on its usefulness, largely related to the diversity of conditions included in the category, viewed as representing at the same time an advantage and a limit.

The NEET category overcomes the narrowness of the youth unemployment definition, to encompass a wide range of youth vulnerabilities, including the economically inactive unemployed and discouraged workers - but also those appearing totally inactive, who are viewed as occupying an unconstructive (and potentially threatening) position in the social topography (Robson, 2008). This is particularly relevant, in the light of the prolonged transition to adulthood we have witnessed over the past 20 years, that has delayed the transition from school to work for many young individuals and increased the complexity of life-course patterns (Bynner \& Parsons, 2002). However, in addition to individuals whose condition raises concern, the NEET label includes young people in transitional states (e.g. in between school and further education, or in between temporary contracts), as well as those who have made the decision not to work or study, to take care of their relatives or young children (Yates \& Payne, 2006). Against this background, some scholars criticize the NEET construct because, due to its heterogeneity, it includes young individuals with very different experiences, characteristics and needs (Cuzzocrea, 2014; Furlong, 2006; Holte 2017; Mac Donald 2011; Sergi et al., 2018). Other studies addressing the transition to adulthood highlight that the NEET label has oversimplified the depiction of young people as a homogeneous urban group struggling with an accumulation of personal, social, and educational risks (i.e. Simões et al., 2017).

Due to the heterogeneity of the NEET category, a variety of approaches have been used to the empirical investigation of the phenomenon. The choice of the age range is symptomatic. Some 
studies focus on very young people aged 16-18, i.e. right after the end of compulsory education (Fahmy, 2006). OECD considers individuals between 15 and 24, whereas the European Commission extends the limits up to 29 years (Batini et al., 2017). Other scholars analyse an even wider group, including not only the very young people but also those between 29 and 34 (Chung et al., 2012). Clearly, the adoption of a wide age range tends to increase the diversity of the NEETs, leading to the inclusion of a variety of situations calling for policy interventions in different domains. Young teenager NEETs are mostly high-school dropouts, pointing to school inclusion policies, while young adults over 30 may require reintegration interventions for those who have already had experience in the labour market.

Altogether, we may regard the NEET concept as useful to the extent that the diversity of conditions encompassed is fully acknowledged. International institutions and scholars have proposed several classifications. A first grouping assumes that NEETs are intrinsically vulnerable, and distinguishes them according to the severity of their condition. The less problematic group is labelled as the essentially confused (young people willing and ready to re-engage as long as the right support and encouragement is provided). The second group is that of the temporarily side-tracked (those dealing with what they consider to be more important in their lives right now). Young people with "high risk of disengagement and disaffection" constitutes the deeply alienated group (Eurofound, 2012; Williamson, 2010; Williamson \& Middlemiss, 1999).

Eurofound (2012) proposed an alternative classification distinguishing vulnerable and nonvulnerable young people. The conventionally unemployed; the unavailable (young carers, young people with family responsibilities and sick or disabled); the disengaged (young people not seeking for jobs or education and not constrained from doing so by other obligations or incapacities, as well as discouraged workers and young people pursuing dangerous and asocial lifestyles); the opportunity-seekers (young people seeking for work or training but holding out for opportunities that they see as benefitting their skills and status); the voluntary NEET (young people travelling or engaged in other activities such as art, music and selfdirected learning).

These classifications are defined in a cross-sectional framework. However, the importance of adopting a longitudinal perspective has emerged in various contributions. Some scholars highlight that the consequences of being NEET may vary greatly according to the length of the permanence in the NEET state (Thompson, 2011). Bynner and Parsons (2002) propose to focus only on the NEET experiencing at least 6 months in the state, implying that shorter episodes should not raise concern. Others analyse the turnover in and out of the NEET state, 
i.e. to what extent young people tend to experience repeated spells out of work and education (Quintini \& Martin, 2006). Tamesberger and Bacher (2014) analyse if the NEET state is permanent or temporary. Few studies introduce a diachronic dimension by exploiting retrospective questions allowing to draw longitudinal information on the duration of unemployment (Sissons \& Jones, 2012). In this respect, Eurofound (2016) makes a significant step towards adopting a longitudinal framework in the analysis of NEETs. Seven subgroups are defined: re-entrants (young people who will soon re-enter employment, education or training); short-term unemployed (for less than a year); long-term unemployed (for more than a year); unavailable due to illness or disability (young people with illness or disability); unavailable due to family responsibilities (those who are caring for children or incapacitated adults, or have other less specific family responsibilities); discouraged workers (young people who have stopped looking for work because they believe that there are no job opportunities for them); other inactive (residual category). This disaggregation has the advantage of taking into account the length of the unemployment spell and to some extent, the reasons for being inactive. However, while the unemployed groups are defined longitudinally, the other groups are defined according to the condition at the time of the survey. We find this approach a bit confusing and not completely satisfactory, as it does not allow to fully acknowledge the persistency in the NEET condition.

Although the previous literature has stressed the importance of longitudinal perspective in the study of the NEET phenomenon, to the best of our knowledge a comprehensive picture of the duration and recurrence of NEET episodes is still missing. Our aim is to fill this gap.

\section{Italy is not a country for young people}

Differently from the UK where the NEET concept was born, in Italy the attention to the NEET phenomenon has emerged only recently and the empirical research is still limited (Cavalca, 2016). This is surprising, given that Italy experiences one of the highest and increasing NEETs shares in the EU (Eurostat, 2017). To state it in Barbieri's terms (Barbieri, 2011) Italy is not a country for young men and women. As highlighted by Rosina (2015) Italy is the biggest producer of NEET in Europe: two million and four hundred people between age 15 and 29, while in Spain, United Kingdom and France they are less than two million. In relative terms, Italy is second to only to Greece (Rosina, 2015).

The NEET phenomenon in Italy is not only characterized by its large size but also for its rapid 
growth over the past decade. According to Eurostat data (Figure 1) the NEET prevalence among individuals of age 20-29 has grown from 22\% to 32\% between 2006 and 2015; the increment has been particularly large for young men (+ 13 p.p.) as compared to women (+7 p.p.). Nonetheless, the share of NEET is substantially higher among females and the gender gap is still larger than in most other Western European countries (Eurofund, 2012).

The literature focuses on some factors that differentiate the NEET experience by gender in Italy (Gaspani, 2017) and agrees that the female over-representation is a result of traditional gender representation and specific labour market characteristics (Carrera, 2012). Family care activities are still largely in charge of women (Rosina, 2015). Moreover, the strong divide between typical and atypical employment and the growth of new forms of work with lower degree of protection exposes all young people but women in particular to the risk of weak working careers (Berton et al. 2009; Del Boca et al. 2012).

[Figure 1 here]

Several measures were recently implemented to promote the inclusion of young people in the labour market, going from training to employment incentives. The only intervention explicitly targeted to NEETs is the Youth Guarantee, designed as a preventive program by the European Union, comprising various actions such as training, apprenticeships, traineeships, promotion of employment or entrepreneurship, counselling and career guidance services. The EU recommendation is that young people should join the program within four months from the beginning of unemployment or exit from formal education. However, given the severity of the context, in Italy the eligible population was extended to include all unemployed and inactive individuals of age 15-29. In three years (2014-2017) more than 400,000 individuals concluded the program and two thirds of them ended up with a job experience of at least 1 year ${ }^{1}$. Altogether, both take-up rates and labour market outcomes are more positive for individuals with higher educational levels.

\section{Data, methods and results}

We analyse the NEET phenomenon in a longitudinal perspective using the Italian longitudinal module in the EU-SILC survey (Statistics on Income and Living Conditions) for the period 2008-

\footnotetext{
1 For more details, see ANPAL (2017).
} 
2014. The Labour Force Survey also provides longitudinal information on employment, unemployment, education and training of young individuals, allowing to identify the NEET condition over time. However, LFS only covers a 15 months period according a to 2-(2)-2 rotation scheme and relies on retrospective questions that do not allow a full reconstruction of individual trajectories over the observed time span. Instead, in EU-SILC individuals are interviewed once a year for four consecutive years. In these interviews, they give full details on their current condition and give retrospective information on the past year on a monthly basis, allowing to reconstruct individual-level sequences of 48 monthly states. ${ }^{2}$

We focus on NEET experiences starting from age 19, the age at which regular students conclude high school. We exclude teenagers because NEETs in this age band are all early school-leavers and their condition is in the exclusive domain of educational policies. In the end, we do observe school dropouts - largely represented by those who did not attain a high school degree - but focus on their histories from early adulthood.

Overall, we analyse the samples of young individuals who are 19-29 years old at the first interviews, observing them in the age ranges 19-23 to 29-33. Due to small sample size, we pool together the data of the four most recent waves (first interview in 2008-2011). We start from wave 2008 because previously there was no information on training and the exact wording of the relevant questions has changed over time.

\subsection{Identifying the NEET young people}

The NEET rate is defined as the share of the population of a given age group who are not employed and not involved in further education or training. The longitudinal module of EUSILC records individuals' monthly condition according to the following classification: employee (full/part-time), self-employed (full/part-time), unemployed, student or in further training, retired, disabled, military service, fulfilling domestic tasks and care responsibilities, other inactivity states. ${ }^{3}$ To analyse individuals careers in and out the NEET state we aggregated these categories into a coarser classification: "employed", "student" or "NEET". We excluded individuals doing military service within the observation window and disabled persons. After dropping the individuals not observed for the entire 4-year span due to

\footnotetext{
${ }^{2}$ Usually, interviews are conducted in March, and the retrospective questions refer to January-December of the previous year.

${ }^{3}$ In its guidelines Eurostat suggests that "If more than one type of activities occur in the same month, priority should be given to economic activity ("main activity: work") over non-economic activity and over inactivity"; and also that "The criterion of most time spent may be useful where applicable."
} 
attrition, our final sample is made of 3,086 individuals. ${ }^{4}$

Some caution is needed when attempting to compare the Eurostat cross-sectional figures and our longitudinal evidence from EU-SILC. Eurostat uses the Labour Force Survey (LFS) and identifies the NEET as the unemployed not in training and the inactive not in education, by referring to the official stringent ILO definition that labels as unemployed only those who are currently not working but available and undertaking an active job-search. Instead, we identify NEETs from individuals' self-declared condition, as they are asked to report their main activity status in a given month. The two options may yield notable differences (Kelly \& McGuinness, 2013; Robson, 2008). According to the former, people who have worked for only few hours in the reference period are classified as employed, whereas according to the selfreported condition they could feel and declare to be unemployed and thus be classified as NEET. Moreover, the use of the self-perceived condition may lead to a substantially different distinction related to voluntariness (e.g. Reiter \& Schlimbach, 2015). Consider discouraged individuals wishing to work but not engaging in active search: according to the ILO definitions they are classified as inactive, while using the self-declaration they could end up as unemployed (Figure 2). Indeed, the self-declared condition is subject to some discretion. However, we regard the use of individuals' self-perceptions as a positive element because it allows overcoming the restrictive ILO definitions that hinder the underemployed by forcing them into the employed category and allows identifying the discouraged youth as unemployed.

[Figure 2 here]

\subsection{A longitudinal classification of individual histories}

Our starting point is the construction of an ex-ante classification of individual "careers" in employment, education or in the NEET condition, based on self-declared condition on a monthly basis. The classification focuses on the persistence in the NEET condition in terms of the total time spent in the NEET state and the number of NEET episodes within the 48 months observation window (Table 1).

Some individuals (almost) never experience the NEET condition (up to 2 months in four years). Among them, we distinguish between those who are Mainly employed and those who are Mainly student. We then define an Episodic NEET group, including the individuals reporting being NEET for 3-11 months. The groups raising more concern are those

\footnotetext{
${ }^{4}$ Wave $1 \mathrm{n}=930$, wave $2 \mathrm{n}=739$, wave $3 \mathrm{n}=635$, wave $4 \mathrm{n}=782$.
} 
experiencing the NEET condition for a longer time. Similar to the definition of long-term unemployment (ILO), we define as long-term NEET those occupying the state for at least 12 months. They are divided into three groups: those resulting NEET for at least 37 months out of 48, that we label the Always NEET, and those resulting NEET for 12-36 months, further split into two groups, according to the recurrence NEET spells. The first includes the individuals who experienced one NEET episode (One long NEET episode), the second those who experienced repeated NEET episodes (Frequently NEET). The reason for this distinction is that on the one side we expect the latter to be less detached from (any type of) activity, as they churn between NEET and employment or education/training; on the other side, the fragmented pattern could be the result of being trapped in a NEET condition hard to leave for good.

[Table 1 here]

\section{Is NEET a temporary or persistent condition?}

A sizeable proportion of young individuals remains outside employment, education and training for an extended period. In Table 2 we show descriptive statistics depicting the sample individual careers in employment, education and in the NEET state, according to the classification proposed in Table 1. We find that almost half of the sample (48.6\%) experiences the NEET condition. Episodic NEET are few (9\%), whereas nearly $40 \%$ of the Italian population in age 19-29 declares being NEET for at least 12 months within the 4-year observation window. The Always NEET are $10.6 \%$ of the total youth population. Thus, when we adopt a longitudinal perspective we acknowledge that the NEET tends to be quite a persistent state (see also the Methodological Notes in the Appendix).

[Table 2 here]

Consistently with cross-sectional evidence, gender differences are marked. Among the nonNEET groups, males are overrepresented in the Mainly employed group and females in the Mainly student group. According to our estimates, long-term NEETs (those in the last three groups) are $42.2 \%$ of the young females and $37.2 \%$ of the young males, with the largest differential observed in the share of Always NEET. 
Visualizing the temporal sequences in the different states allows getting a better grasp of the main patterns across NEET and non-NEET states (Figure 3). Table 3 complements the graphical representation by providing information on the average duration in each state by group type.

[Figure 3 here]

[Table 3 here]

The two never-NEET groups are internally quite homogenous. The large majority of those classified as Mainly employed are employed for the entire period of observation, and the same occurs among those in the Mainly student category. The Episodic NEET group is composed by two main subsets characterized by a strong prevalence of either employment or education or training. Altogether, individuals in this group experience only very short NEET spells that can be interpreted as physiologic or frictional inactivity; the average number of NEET months is 6. Moving to the most critical segments, people in the One long NEET episode and Frequently NEET categories occupy the NEET state for a similar amount of time (20-24 months). However, individuals in the former spend more time in education or training, whereas individuals in the latter spend more time in employment, and display fragmented sequences with short employment spells alternating short NEET spells. In these groups, some individuals start as students and end up as NEET, some start as NEET and enter employment, others start as employed and eventually become NEET. Instead, we observe few individuals starting as NEET and re-entering education or training, suggesting that these options are not pursued as a strategy to increase the chances to find a job.

The Always NEET group is almost entirely composed by individuals starting in the NEET state and remaining NEET for the entire observation period (on average, the number of NEET months is 46 out of 48). Notice that due to left and right censoring, this is likely to be an underestimate of the duration of NEET spell for the individuals in these groups.

\subsection{Socio-demographic composition of long-term NEET}

The longitudinal profiles detailed in terms of socio-demographic characteristics are shown in Table 4. We do not consider social background because information on parental education and occupation is unavailable for individuals not living with their parents $(20 \%$ of the sample). 
The Mainly employed subgroup is composed largely by men, individuals living in the North and older than the average. The Mainly student are generally younger and with a larger share of women. Northerners are overrepresented among the Episodic NEET, while individuals living on the South, are relatively few in particular among women; the share of youngsters with tertiary education is particularly large in this subgroup.

Moving to long-term NEET subgroups, we observe that the majority of them lives in the South. The males' territorial distribution is particularly skewed for men: despite representing 39\% of the Italian male sample, $74 \%$ of the males in the Always NEET group and $40-50 \%$ of those in the One long NEET episode and Frequently NEET live in the South. Females are overrepresented among the Always NEET (but not in the other two long-term NEET subgroups). The majority of long-term NEETs have high-school level education, reflecting the education distribution in the population at large; however, low-educated individuals prevail among Always NEET males. The share of tertiary educated individuals in the One long NEET episode and Frequently NEET subgroups is comparable to that of the population, while the corresponding share among the Always NEET is relatively large for women (9\%), but almost nil for males.

[Table 4 here]

\subsection{Risk profiles}

We now analyse the determinants of the longitudinal patterns with multinomial logit models. The dependent variable is defined in Table 1 and explanatory variables are the sociodemographic characteristics at the first interview listed in Table 4 and dummies for survey wave. Gender is interacted with age and educational levels.

The risk profiles for individuals of first wave 2011 are shown in Table 5. First, we observe that the long-term-NEET conditional probability is higher than $20 \%$ for all individual profiles (Table 5). Thus, all socio-demographic groups are exposed to a substantial risk of experiencing the NEET condition for at least one year out of four. The most at risk are loweducated males (67-73\%) and older women (64-85\%) in southern regions, whereas those facing the lowest long-term NEET risk are males and females in the younger age group, living in the North, with at least upper secondary education.

[Table 5 here] 
In Figure 4, we plot the predicted probabilities of being in each of the longitudinal subgroup by gender and educational level. Although the difference is not highly statistically significant, we observe a higher conditional probability of experiencing short NEET spells for individuals with tertiary education, probably reflecting a job shopping activity after graduation. Instead, tertiary education has a clear protective role against being Always NEET, in particular for men, as we discuss further below. Altogether, the risk of being long-term NEET is much higher for individuals not attaining a high school qualification, although the difference is substantial only when focusing on the probability of being Always NEET. Interestingly, this result is not fully consistent with the cross-sectional evidence: according to Eurofund (2016) the probability of being NEET in 2013 was higher for individuals with an upper secondary school degree than for those with a lower educational level. The longitudinal perspective shows that despite not being at higher risk of being NEET in a given month, the less educated have a substantially higher probability of remaining NEET for a long time.

[Figure 4 here]

Relevant interaction effects are observed also between gender and age at the first interview (Figure 5). As already highlighted, females are more likely to be in the Never NEET, Mainly student and less likely to be in the Never NEET, Mainly employed group. However, while the gender gap in the probability of belonging to the first group increases with age at the first interview, the female advantage in the second disappears at older ages (when also tertiary education could be completed). The probability of being in the Episodic NEET, One long episode and Frequently NEET groups are similar for males and females at all ages. Instead, while we observe no gender differences in the probability of falling in the Always NEET category among the youngest group, from age 24 the risk for women and men starts diverging. As we will discuss in the next section, the pattern by age, as well as the milder protective effect of high education for women against being Always NEET reflect the low participation of Italian females in the labour market, observed in particular among women with family care duties.

[Figure 5 here]

\subsection{Long-term NEET: unemployment or inactivity?}


In the light of the debate around the diversity of situations encompassed in the NEET category, gaining more knowledge on the characteristics of long-term NEET is of great importance to draw meaningful policy indications. The first distinction we need to address is related to iness. Are long-term NEET mainly unemployed or inactive? Who are those characterized by long inactivity spells?

Our hypothesis is that if family duties are a major driver of the large share of long-term NEET among Italian women, many women (especially in the older age bands) should report being inactive. Indeed, while unemployment is unarguably expression of the individual's willingness to work, self-reported inactivity may be harder to interpret, because it could indicate a voluntary state or simply reflect discouragement, due to the difficulty of finding a job or reconciling family and work chores.

We now visualize individuals' sequences according to self-declarations in the longitudinal groups where the NEET experience is more relevant, by age and gender (Figure 6). The NEET state is now split into two sub-states: unemployment and inactivity. The unemployment portion definitely prevails, confirming that most often those who are not in employment, nor in education or training, feel unemployed. The orange portion, very small for men, is somewhat larger among women. Yet, this portion becomes predominant (almost $60 \%$ of the NEET person-months) only among women in age 24-29 in the Always NEET group.

A remark is in order. According to Eurofund (2012), the share of unemployed within NEETs in Italy is generally low as compared to the other EU countries, around 35\%, whereas in our data the average cross-sectional share is $74 \%$. Yet, the inconsistency is only apparent. As highlighted above, the attribution of the unemployed state in Eurofund is based on LFS data and the official ILO definition, whereas we use the individuals' self-declared condition (see Figure 2). This entails a potentially large difference in the relative portion of unemployed. In this respect, our study allows underscore that when focusing on individuals' self-reports the NEET issue among young adult stems out as being largely an issue of unemployment.

We then consider the relative share of time in unemployment or inactivity for the Always NEET. While men nearly always report being unemployed, this is not the case for women. Time in unemployment increases substantially with education, from an average of 19 months for women with no high school diploma, to 28 months for women with a high school qualification and 36 months for the university graduated.

Focusing on family duties gives further elements to the interpretation of the large share of long-term NEETs among females from age 24. In Table 6 we analyse the relation between 
household composition and longitudinal sequences, for young men and women. ${ }^{5}$ Among individuals in the One long NEET episode and Frequently NEET groups, those living with their parents are predominant for both genders. This is even more the case for men in the Always NEET group (92\%), whereas among women in the same group the share drops to $44 \%$. In this group, women with their own family and children are almost $46 \%$, against a percentage of $0.7 \%$ among men.

[Figure 6 here]

[Table 6 here]

Our last piece of evidence relates family composition to the relative importance of unemployment vs inactivity in long-term NEET sequences. The average share of NEET person/months declared as inactive by gender and household composition is shown in Table 7. Months in inactivity are largely the minority for men and for young women living with their parents, contradicting the stereotyped depiction of the NEET as idle individuals entirely living off their families of origin. The share of months in inactivity grows substantially among females in all other subgroups, although unemployment remains the major reason for being NEET. Inactivity is predominant only for women with children.

[Table 7 here]

Altogether, these results confirm that the high share of long-term NEET among women in the oldest age group reflects the tendency for many women in Italy to stay out of the labour market when they have children and family duties, although the choice is not necessarily always a voluntary choice. The effect is mitigated by education, as women with a university degree have a lower chance of falling in the Always NEET group; if they do, they are more likely to report being unemployed rather than inactive as compared to women with lower educational attainment.

\section{Summary and conclusions}

\footnotetext{
${ }^{5}$ As for the other socio-demographic variables, we consider both living conditions and presence of children as measured at the first interview.
} 
In this article, we provide a longitudinal account of the NEET phenomenon in Italy. This perspective allows underscoring aspects of the phenomenon that are not captured by crosssectional analyses. We estimate that nearly $40 \%$ of Italian young people experience the NEET condition for at least 12 months within a 4-year observation window. More specifically, 16.5\% experience one long NEET spell (20 months on average), 12.5\% experience at least two NEET spells (2 years in total on average), whereas more than $10 \%$ remain stuck into the NEET condition for the entire (or almost entire) period. We conclude that the long-term NEET condition does not involve few marginalized individuals, but is a massive phenomenon. Moreover, our results show that all socio-demographic groups are exposed to a sensible risk of falling into a long-term NEET condition. However, those more at risk are individuals with a low level of education and women, in particular in the South of Italy. We now review the main findings for gender and education effects and attempt to draw some general policy implications.

(i) Education. Our findings show that despite the risk of being NEET at a given point of time is highest for young individuals with upper secondary schooling (Eurofund 2016), if youngsters without a high school diploma become NEET, they are more likely either to remain trapped for a long time or to move back and forth between short NEET and employment spells.

At the national level, the share of those not reaching an upper secondary qualification has reduced substantially over time, approaching $20 \%$ for the most recent cohorts. Still, it is a large group. This highlights the need for policies specifically targeted to them. Given the lower participation in the Youth Guarantee program of individuals with a low level of education (ANPAL 2017), it would be sensible to design interventions aimed at increasing their take-up rate. In parallel, public policies aimed at fostering participation to the school system are also called for. A major intervention could be raising time in comprehensive schooling (currently up to age 14) to age 16, to elevate the general competences of those who do not attend upper secondary education. A reform of the Italian VET educational system is also needed, because vocational high schools offer only low quality general education and vocational higher education is largely underdeveloped. Moreover, vocational training programs designed to acquire the skills needed in the labour market (provided at the regional level) are basically inexistent in the South, where the majority of long-term NEETs live. In addition, despite the positive trends, Italy is still lagging behind most other European countries in the share of young individuals with a tertiary degree (Eurostat 2014), so it is urgent to increase higher 
education participation and completion. However, if it is true that tertiary education exerts a protective effect against being NEET, we must bear in mind the risk of over-qualification for graduates in a labour market where qualified jobs are currently scant. Indeed, well-targeted industrial policy interventions aimed at increasing (qualified) labour demand are crucial (Sergi et al., 2018).

(ii) Gender. The women's higher risk of being long-term NEET manifests in the older age band (24-29), and in particular in the probability of being in the Always NEET group. Moreover, the protective effect of education is weaker for women: the estimated risk of being Always NEET among tertiary educated women is $9 \%$, whereas it is negligible for men. Analyses by family composition show that women with children drive these patterns, and confirm that women are much more exposed to the risk of remaining out of the "work for the market" world for a long time, in particular when they have family responsibilities. This is hardly surprising, given the strongly unequal gender division of family care chores and the low participation to the labour market of Italian women even across recent cohorts. Analysing the relative importance of unemployment vs. inactivity within NEET spells provides further insights. Contrary to the cross-sectional NEET depiction of official statistics that differently from most other EU countries describe the Italian NEET as mainly inactive (Eurofund 2012), our findings suggest that the NEET phenomenon among Italian young adults is mainly an issue of unemployment. Comparing our findings with official figures on youth unemployment and long-term unemployment confirms that discouragement is a major issue in the current Italian labour market. Italian females with children, the majority of which report being "performing domestic tasks", represent the only exception to this portrait. Still, a sizable share of these women - most of whom are low educated, but a significant share having a tertiary degree define themselves as being mainly unemployed, indicating an unsatisfied wish or need to work. This highlights the need for appropriate work-family conciliation policies, such as parttime, parental leave, childcare services (Del Boca \& Vuri, 2007; Saraceno, 2011), perhaps accompanied by (re-)training of skills that might have become obsolete due to the long detachment from employment/education.

We now turn to methodological conclusions. Having contributed to shift the attention from youth unemployment to a broader range of vulnerabilities, we regard the NEET category as being valuable as a conceptual tool. The prevalence of NEETs is a useful indicator in a comparative perspective, because it gives an immediate grasp of the size of the youth population in a condition of potential vulnerability. However, knowledge of the NEET 
prevalence in itself does not help designing policies to address the phenomenon, unless it is possible to distinguish the different subgroups empirically and quantify them. For this reason, as other scholars in field (e.g. Cuzzocrea, 2014; Mac Donald 2011; Sergi et al., 2018) we have some reservations about the usefulness of the NEET category as analytic tool. In addition to being very heterogeneous, the NEET category is problematic also because it does not univocally identify individuals in need: on the one side, it may include some non-vulnerable individuals (in particular, those exercising the choice of not working or studying); on the other, it excludes the underemployed working only a few hours a week.

Nonetheless, the approach adopted in this paper may help overcoming these limitations:

(i) Despite being inevitably subject to some discretion, data on the self-reported condition has the advantage of allowing to identify those wishing to work. Differently from data based on the official definition of unemployment, this information reveals how people actually feel and whether they perceive themselves as unemployed, even if they do not undertake an active job-search. Hence, the self-reported condition allows a more informative disaggregation of the NEETs into subgroups with different problems and needs. Moreover, those holding precarious jobs and working only a few hours a week may define themselves as unemployed, and may thus be included among NEETs (Figure 2).

(ii) The longitudinal outlook helps identifying the vulnerable youth population. In this perspective, analyzing the extent to which the NEET phenomenon is a persistent or a transient condition was the explicit goal of our research. The underlying assumption is that being NEET may eventually lead to social exclusion if it is a long-lasting condition, or if individuals keep churning in and out the NEET state. Indeed, we cannot rule out that some individuals classified as long-term NEET might be voluntarily engaged in activities that are not recognized as work or formal education or training, and therefore should be considered not vulnerable. Still, we expect this share to represent only a minority of individuals. We can discuss at length whether women with family responsibilities declaring to be inactive (not unemployed) - who make a significant share of the Always NEET group in our analysis - are vulnerable, and whether it would be socially desirable that they work also for the market. This goes beyond the scope of the present work and we leave it to further discussion.

\section{References}

ANPAL (2017) L'attuazione della Garanzia Giovani in Italia. Rapporto trimestrale 3/2017 (ANPAL: www.anpal.gov.it). 
Barbieri, P. (2011) Italy: No Country for Young Men (and Women): The Italian Way of Coping with Increasing Demands for Labour Market Flexibility and Rising Welfare Problems, in: H.-P. Blossfeld, S. Buchholz, D. Hofäcker \& K. Kolb, (Eds.) Globalized Labour Markets and Social Inequality in Europe, pp. (UK: Palgrave Macmillan).

Batini, F., Corallino, V., Toti, G. \& Bartolucci, M. (2017) NEET: A Phenomenom Yet to Be Explored, Interchange, 48, pp. 19-37.

Berton, F., Richiardi, M. \& Sacchi, S. (Eds.) (2009) Flex-insecurity. Perché in Italia la flessibilità diventa precarietà (Bologna: Il Mulino).

Bynner, J. \& Parsons, S. (2002) Social Exclusion and the Transition from School to Work: The Case of Young People Not in Education, Employment, or Training (NEET), Journal of Vocational Behavior, 60, pp. 289-309.

Carrera, L. (2012) The Neet. The lost bet, Italian Sociological Review, 2, pp. 106-115.

Cavalca, G. (2016) Young people in transitions: conditions, indicators and policy implications. To NEET or not to NEET?, in: G. Coppola \& N. O'Higgins, (Eds.) Youth and the Crisis. Unemployment, education and health in Europe, pp. (Abingdon: Routledge).

Chung, H., Bekker, S. \& Houwing, H. (2012) Young people and the post-recession labour market in the context of Europe 2020, Transfer: European Review of Labour and Research, 18, pp. 301-317.

Cuzzocrea, V. (2014) Projecting the category of NEET into the future, in: Directorate Council of Europe, (Ed.) Perspectives on youth, pp. 69-82 (Strasbourg Cedex: Council of Europe Publishing).

Del Boca, D., Mencarini, L. \& Pasqua, S. (2012) Valorizzare le donne conviene. Ruoli di genere nell'economia italiana (Bologna: Il Mulino).

Del Boca, D. \& Vuri, D. (2007) The mismatch between employment and child care in Italy: the impact of rationing, Journal of Population Economics, 20, pp. 805-832.

Eurofound (2012) NEETs - Young people not in employment, education or training: Characteristics, costs and policy responses in Europe (Luxembourg: Publications Office of the European Union).

Eurofound (2016) Exploring the diversity of NEETs (Luxembourg: Publications Office of the European Union).

Eurostat (2017) Statistics on young people neither in employment nor in education or training Eurostat. Statitics Explained. Available at: http://ec.europa.eu/eurostat/statisticsexplained/index.php/Statistics_on_young_people_neither_in_employment_nor_in_educ ation_or_training.

Fahmy, E. (2006) Youth, poverty and social exclusion, in: C. Pantazis, D. Gordon \& R. Levitas, (Eds.) Poverty and social exclusion in Britain: The millennium survey, pp. (Bristol: Policy Press).

Furlong, A. (2006) Not a very NEET solution: representing problematic labour market transitions among early school-leavers, Work, Employment and Society, 20, pp. 553-569.

Gaspani, F. (2017) NEET: questioni definitorie e linee guida all'utilizzo della categoria, Sociologia e Politiche Sociali, 20, pp. 111-134.

Holte, B. H. (2018) Counting and Meeting NEET Young People:Methodology, Perspective and Meaning in Research on Marginalized Youth, Young, 26, pp. 1-16.

Kahn, L. M. (2007) The Impact of Employment Protection Mandates on Demographic Temporary Employment Patterns: International Microeconomic Evidence, The Economic Journal, 117, pp. F333-F356.

Kelly, E. \& McGuinness, S. (2013) The impact of the recession on the structure and labour market success of young NEET individuals in Ireland, Working paper of the Economic and Social Research Institute (ESRI), 465.

MacDonald, R. (2011) Youth transitions, unemployment and underemployment, Journal of Sociology, 47, pp. 427-444. 
Quintini, G. \& Martin, S. (2006) Starting Well or Losing their Way?: The Position of Youth in the Labour Market in OECD Countries, OECD Social, Employment and Migration Working Papers, 39, pp. 1-70.

Reiter, H. \& Schlimbach, T. (2015) NEET in disguise? Rival narratives in troubled youth transitions, Educational Research, 57, pp. 133-150.

Roberts, S. (2011) Beyond 'NEET' and 'tidy' pathways: considering the 'missing middle' of youth transition studies, Journal of Youth Studies, 14, pp. 21-39.

Robson, K. (2008) Becoming NEET in Europe: A Comparison of Predictors and Later-Life Outcomes, Global Network on Inequality Mini-Conference, New York City.

Rosina, A. (2015) NEET. Giovani che non studiano e non lavorano (Milano: Vita e Pensiero).

Saraceno, C. (2011) Childcare needs and childcare policies: A multidimensional issue, Current Sociology, 59, pp. 78-96.

Sergi, V., Cefalo, R. \& Kazepov, Y. (2018) Young people's disadvantages on the labour market in Italy: reframing the NEET category, Journal of Modern Italian Studies, 23, pp. 41-60.

Serrano Pascual, A. \& Martín Martín, P. (2017) From 'Employab-ility' to 'Entrepreneurial-ity' in Spain: youth in the spotlight in times of crisis, Journal of Youth Studies, 20, pp. 798-821.

Simões, F., Meneses, A., Luís, R. \& Drumonde, R. (2017) NEETs in a rural region of Southern Europe: perceived self-efficacy, perceived barriers, educational expectations, and vocational expectations, Journal of Youth Studies, pp. 1-18.

Sissons, P. \& Jones, K. (2012) Lost in Transition? The Changing Labour Market and Young People not in Employment, Education or Training (London: The Work Foundation Lancaster University).

Tamesberger, D. \& Bacher, J. (2014) NEET youth in Austria: a typology including sociodemography, labour market behaviour and permanence, Journal of Youth Studies, 17, pp. 1239-1259.

Thompson, R. (2011) Individualisation and social exclusion: the case of young people not in education, employment or training, Oxford Review of Education, 37, pp. 785-802.

UCW (2013) NEET youth dynamics in Indonesia and Brazil. A cohort analysis (Rome: Understanding Children's Work Report).

Williamson, H. (2010) Delivering a 'NEET' solution: An essay on an apparently intractable problem, in: S. Upton, (Ed.) Engaging Wales' disengaged youth, pp. (Cardiff: Institute of Welsh Affairs).

Williamson, H. \& Middlemiss, R. (1999) The emperor has no clothes: cycles of delusion in community interventions with disaffected young men, Youth and Policy, 63, pp. 13-25.

Yates, S. \& Payne, M. (2006) Not so NEET? A Critique of the Use of 'NEET' in Setting Targets for Interventions with Young People, Journal of Youth Studies, 9, pp. 329-344. 
Table 1: Individual careers in and out the NEET state

\begin{tabular}{ll}
\hline Label & Description \\
\hline $\begin{array}{l}\text { Never NEET, Mainly } \\
\text { employed }\end{array}$ & $\begin{array}{l}<3 \text { months NEET } \\
\text { months in employment }>\text { months in education or training }\end{array}$ \\
\hline $\begin{array}{l}\text { Never NEET, Mainly } \\
\text { student }\end{array}$ & $\begin{array}{l}<3 \text { months NEET } \\
\text { months in education or training }>\text { months in employment }\end{array}$ \\
\hline Episodic NEET & $3-11$ months NEET \\
\hline $\begin{array}{l}\text { One long NEET } \\
\text { episode }\end{array}$ & $\begin{array}{l}12-36 \text { months NEET } \\
\text { One NEET spell }\end{array}$ \\
\hline Frequently NEET & $\begin{array}{l}12-36 \text { months NEET } \\
\text { Two or more NEET spells }\end{array}$ \\
\hline Always NEET & $37+$ months NEET \\
\hline
\end{tabular}

Table 2. Longitudinal NEET sequences by gender

\begin{tabular}{|c|c|c|c|c|c|c|}
\hline \multirow[b]{2}{*}{ Sequences } & \multicolumn{2}{|c|}{ Overall } & \multicolumn{2}{|c|}{ Male } & \multicolumn{2}{|c|}{ Female } \\
\hline & $\%$ & $\mathrm{~N}$ & $\%$ & $\mathrm{~N}$ & $\%$ & $\mathrm{~N}$ \\
\hline Never NEET, mainly employed & 27.3 & 841 & 34.0 & 531 & 20.3 & 310 \\
\hline Never NEET, mainly student & 24.1 & 744 & 20.3 & 317 & 28.0 & 427 \\
\hline Episodic NEET & 9.0 & 279 & 8.5 & 133 & 9.6 & 146 \\
\hline One long NEET episode & 16.5 & 508 & 15.5 & 242 & 17.4 & 266 \\
\hline Frequently NEET & 12.5 & 387 & 12.8 & 200 & 12.3 & 187 \\
\hline Always NEET & 10.6 & 327 & 8.8 & 137 & 12.5 & 190 \\
\hline Total & 100 & 3086 & 100 & 1560 & 100 & 1526 \\
\hline
\end{tabular}

Table 3: Average $n^{\circ}$ of months spent in each state by group type

\begin{tabular}{lrrr}
\hline & Employed & Student & NEET \\
\hline Never NEET, mainly employed & 45.7 & 2.2 & 0.1 \\
Never NEET, mainly student & 2.5 & 45.4 & 0.1 \\
Episodic NEET & 28.3 & 13.5 & 6.2 \\
One long NEET episode & 14.6 & 13.3 & 20.1 \\
Frequently NEET & 17.6 & 6.6 & 23.8 \\
Always NEET & 1.5 & 0.4 & 46.2 \\
\hline
\end{tabular}

Table 4: Socio-demographic characteristics by group type.

\begin{tabular}{|c|c|c|c|c|c|c|c|c|c|c|c|c|c|c|}
\hline & \multirow{3}{*}{$\begin{array}{c}\text { AGE } \\
\text { Mean }\end{array}$} & \multirow{3}{*}{$\begin{array}{l}\text { SEX } \\
\% \mathrm{~F}\end{array}$} & \multicolumn{6}{|c|}{ AREA } & \multicolumn{6}{|c|}{ EDUCATION } \\
\hline & & & \multicolumn{2}{|c|}{$\%$ North } & \multicolumn{2}{|c|}{$\%$ Centre } & \multicolumn{2}{|c|}{ \%South } & \multicolumn{2}{|c|}{ \%Low } & \multicolumn{2}{|c|}{$\%$ Medium } & \multicolumn{2}{|c|}{$\%$ High } \\
\hline & & & M & $\mathrm{F}$ & $\mathrm{M}$ & $\mathrm{F}$ & $\mathrm{M}$ & $\mathrm{F}$ & $\mathrm{M}$ & $\mathrm{F}$ & $\mathrm{M}$ & $\mathrm{F}$ & $\mathrm{M}$ & $\mathrm{F}$ \\
\hline Never NEET, mainly empl. & 25.4 & 36.9 & 52.1 & 59.3 & 23.2 & 24.2 & 24.7 & 16.5 & 26.1 & 12.6 & 64.6 & 67.0 & 9.3 & 20.4 \\
\hline Never NEET, mainly stud. & 21.7 & 57.4 & 44.2 & 39.6 & 23.0 & 23.2 & 32.8 & 37.2 & 11.4 & 9.4 & 82.3 & 81.9 & 6.3 & 8.7 \\
\hline Episodic NEET & 24.3 & 52.3 & 48.9 & 54.1 & 17.3 & 17.8 & 33.8 & 28.1 & 27.1 & 12.5 & 60.1 & 63.2 & 12.8 & 24.3 \\
\hline One long NEET episode & 23.8 & 52.4 & 31.4 & 34.2 & 16.9 & 20.3 & 51.7 & 45.5 & 28.2 & 22.4 & 62.7 & 61.4 & 9.1 & 16.3 \\
\hline Frequently NEET & 23.9 & 48.3 & 32.5 & 33.2 & 17.0 & 26.2 & 50.5 & 40.6 & 36.6 & 24.6 & 57.4 & 58.3 & 6.1 & 17.1 \\
\hline Always NEET & 24.3 & 58.1 & 11.7 & 24.2 & 14.6 & 14.7 & 73.7 & 61.1 & 52.3 & 36.0 & 47.0 & 55.0 & 0.7 & 9.0 \\
\hline ENTIRE SAMPLE & 23.9 & 49.5 & 41.0 & 41.3 & 20.1 & 21.7 & 38.9 & 37.0 & 27.1 & 17.8 & 65.1 & 67.3 & 7.8 & 14.9 \\
\hline
\end{tabular}


Table 5. Risk profile of experiencing the One long NEET spell, Frequently NEET and Always NEET histories (2011-2014)

\begin{tabular}{|c|c|c|c|c|c|c|c|c|c|c|c|c|c|c|c|}
\hline & & & & $\begin{array}{l}\mathrm{P} \text { (one } \\
\text { long) }\end{array}$ & $P($ freq.) & P(alw.) & $\begin{array}{l}\text { P(long- } \\
\text { term) }\end{array}$ & & & & & $\begin{array}{l}\mathrm{P} \text { (one } \\
\text { long) }\end{array}$ & $P$ (freq.) & P(alw.) & $\begin{array}{l}\text { P(long- } \\
\text { term) }\end{array}$ \\
\hline \multirow{18}{*}{$\frac{0}{\pi}$} & \multirow{6}{*}{$\begin{array}{l}5 \\
\vdots \\
z\end{array}$} & \multirow{3}{*}{$\underset{⿱}{\mathbb{v}}$} & low & 0.17 & 0.18 & 0.10 & 0.45 & & \multirow{6}{*}{ Ẽ } & \multirow{3}{*}{ 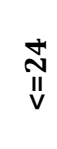 } & low & 0.2 & 0.15 & 0.13 & 0.48 \\
\hline & & & med & 0.12 & 0.10 & 0.04 & 0.26 & & & & med & 0.14 & 0.08 & 0.04 & 0.26 \\
\hline & & & high & 0.14 & 0.10 & 0.02 & 0.26 & & & & high & 0.15 & 0.08 & 0.02 & 0.25 \\
\hline & & \multirow{3}{*}{$\stackrel{\text { L }}{\text { II }}$} & low & 0.14 & 0.11 & 0.07 & 0.32 & & & \multirow{3}{*}{$\stackrel{\text { ñ }}{\|}$} & low & 0.17 & 0.15 & 0.2 & 0.52 \\
\hline & & & med & 0.12 & 0.08 & 0.03 & 0.23 & & & & med & 0.17 & 0.13 & 0.09 & 0.39 \\
\hline & & & high & 0.14 & 0.08 & 0.01 & 0.23 & & & & high & 0.19 & 0.13 & 0.05 & 0.37 \\
\hline & \multirow{6}{*}{$\stackrel{\Xi}{\Xi}$} & \multirow{3}{*}{$\underset{⿱ 亠 凶}{\mathbb{v}}$} & low & 0.18 & 0.22 & 0.15 & 0.55 & \multirow{6}{*}{ 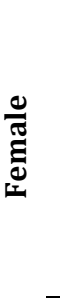 } & \multirow{6}{*}{. } & \multirow{3}{*}{$\underset{⿱ N}{\mathbb{V}}$} & low & 0.21 & 0.17 & 0.18 & 0.56 \\
\hline & & & med & 0.13 & 0.12 & 0.05 & 0.30 & & & & med & 0.14 & 0.09 & 0.06 & 0.29 \\
\hline & & & high & 0.15 & 0.13 & 0.02 & 0.30 & & & & high & 0.16 & 0.1 & 0.03 & 0.29 \\
\hline & & \multirow{3}{*}{$\stackrel{\text { Ln }}{\text { II }}$} & low & 0.16 & 0.15 & 0.10 & 0.41 & & & \multirow{3}{*}{$\stackrel{\text { ñ }}{\Lambda}$} & low & 0.18 & 0.2 & 0.28 & 0.66 \\
\hline & & & med & 0.15 & 0.11 & 0.04 & 0.30 & & & & med & 0.18 & 0.16 & 0.14 & 0.48 \\
\hline & & & high & 0.17 & 0.11 & 0.02 & 0.30 & & & & high & 0.22 & 0.17 & 0.07 & 0.46 \\
\hline & \multirow{6}{*}{ ڤ્ } & \multirow{3}{*}{$\underset{⿱ 亠 凶}{\mathbb{v}}$} & low & 0.22 & 0.21 & 0.30 & 0.73 & & & \multirow{3}{*}{ 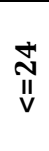 } & low & 0.24 & 0.2 & 0.28 & 0.72 \\
\hline & & & med & 0.19 & 0.14 & 0.12 & 0.45 & & & & med & 0.2 & 0.1 & 0.13 & 0.43 \\
\hline & & & high & 0.22 & 0.15 & 0.06 & 0.43 & & $\stackrel{\Xi}{\Xi}$ & & high & 0.23 & 0.11 & 0.07 & 0.41 \\
\hline & & \multirow{3}{*}{$\stackrel{1}{N}$} & low & 0.24 & 0.18 & 0.25 & 0.67 & & s & \multirow{3}{*}{$\stackrel{10}{\pi}$} & low & 0.19 & 0.17 & 0.49 & 0.85 \\
\hline & & & med & 0.25 & 0.14 & 0.12 & 0.51 & & & & med & 0.24 & 0.17 & 0.3 & 0.71 \\
\hline & & & high & 0.28 & 0.15 & 0.06 & 0.49 & & & & high & 0.29 & 0.19 & 0.16 & 0.64 \\
\hline
\end{tabular}

NOTE. The estimated probability of Long-term NEET is the sum of the other values, and is reported in bold.

Table 6: Family composition of young people experiencing a long-term NEET condition, by gender

\begin{tabular}{lccccccccc}
\hline & \multicolumn{2}{c}{$\begin{array}{c}\text { One long } \\
\text { NEET episode }\end{array}$} & \multicolumn{2}{c}{$\begin{array}{c}\text { Frequently } \\
\text { NEET }\end{array}$} & \multicolumn{2}{c}{$\begin{array}{c}\text { Always } \\
\text { NEET }\end{array}$} & \multicolumn{2}{c}{ Entire sample } \\
\hline & Male & Female & Male & Female & Male & Female & Male & Female \\
\hline Family composition & & & & & & & & \\
With parents & $81.8 \%$ & $75.6 \%$ & $84.0 \%$ & $60.4 \%$ & $92.0 \%$ & $44.2 \%$ & $79.5 \%$ & $69.3 \%$ \\
Single & $11.2 \%$ & $5.3 \%$ & $7.0 \%$ & $7.5 \%$ & $4.4 \%$ & $2.1 \%$ & $9.2 \%$ & $7.0 \%$ \\
With partner & $2.1 \%$ & $4.5 \%$ & $1.5 \%$ & $7.0 \%$ & $0.7 \%$ & $4.7 \%$ & $4.1 \%$ & $5.3 \%$ \\
With partner and children & $4.1 \%$ & $10.5 \%$ & $7.5 \%$ & $20.3 \%$ & $0.7 \%$ & $45.8 \%$ & $6.7 \%$ & $15.3 \%$ \\
Others* & $0.8 \%$ & $4.1 \%$ & $0.0 \%$ & $4.8 \%$ & $2.2 \%$ & $3.2 \%$ & $0.5 \%$ & $3.1 \%$ \\
\hline
\end{tabular}

* Others include: a) individuals living with their parents and children; b) single parents 
Table 7: Average share of NEET months in inactivity (vs unemployment) by family composition at the first interview

\begin{tabular}{lcccccc}
\hline & \multicolumn{2}{c}{$\begin{array}{c}\text { One long } \\
\text { NEET episode }\end{array}$} & \multicolumn{2}{c}{$\begin{array}{c}\text { Frequently } \\
\text { NEET }\end{array}$} & \multicolumn{2}{c}{$\begin{array}{c}\text { Always } \\
\text { NEET }\end{array}$} \\
\cline { 2 - 7 } & Male & Female & Male & Female & Male & Female \\
\hline Overall & $13.4 \%$ & $28.4 \%$ & $13.7 \%$ & $27.4 \%$ & $12.3 \%$ & $47.9 \%$ \\
Family composition & & & & & & \\
With parents & $14.3 \%$ & $18.2 \%$ & $15.0 \%$ & $17.5 \%$ & $13.4 \%$ & $16.0 \%$ \\
Single & $2.7 \%$ & $43.0 \%$ & $6.2 \%$ & $14.6 \%$ & $0.0 \%$ & $37.3 \%$ \\
With partner & $24.2 \%$ & $37.8 \%$ & $0.0 \%$ & $25.2 \%$ & $0.0 \%$ & $52.6 \%$ \\
With partner and children & $16.1 \%$ & $74.1 \%$ & $7.1 \%$ & $50.7 \%$ & $0.0 \%$ & $78.3 \%$ \\
Others* & $0.0 \%$ & $45.2 \%$ & - & $63.5 \%$ & $0.0 \%$ & $41.7 \%$ \\
\hline
\end{tabular}

* Others include: a) individuals living with their parents and children; b) single parents

Figure 1: Share of individuals age 20-29 not in employment, nor in education or training Source: Own computation on Eurostat data

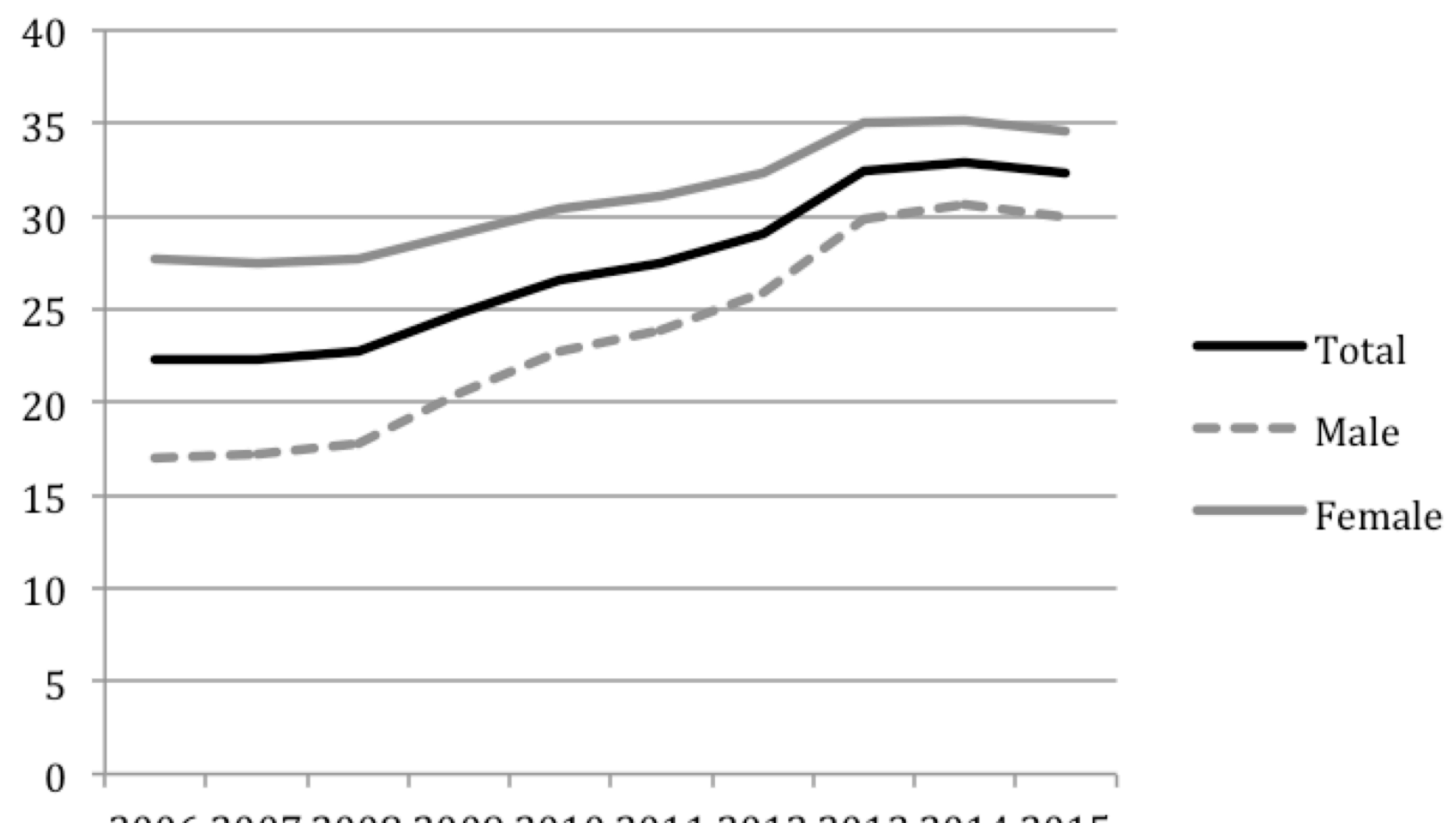

2006200720082009201020112012201320142015 
Figure 2 Conceptual differences between the NEET: official unemployment definition (ILO) and self-perceived condition.

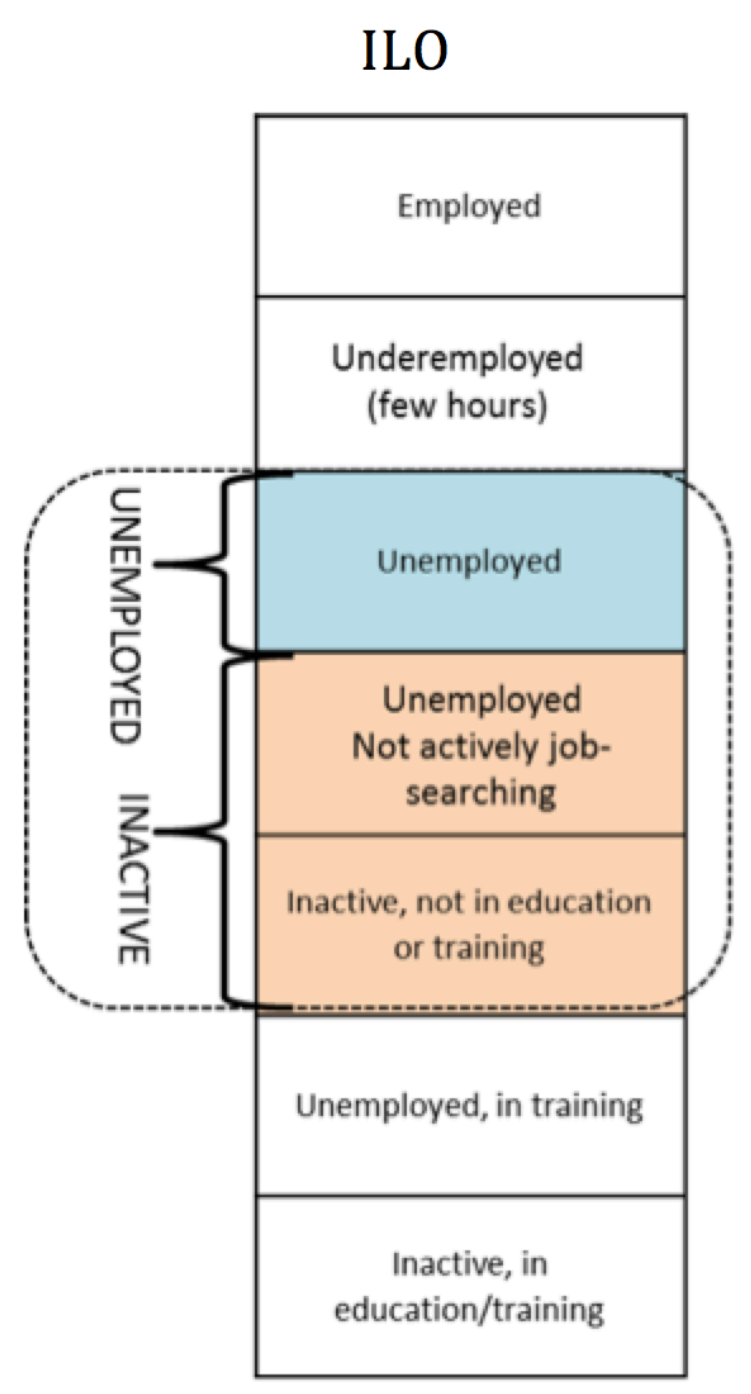

SELF-DEClaRed CONDITION

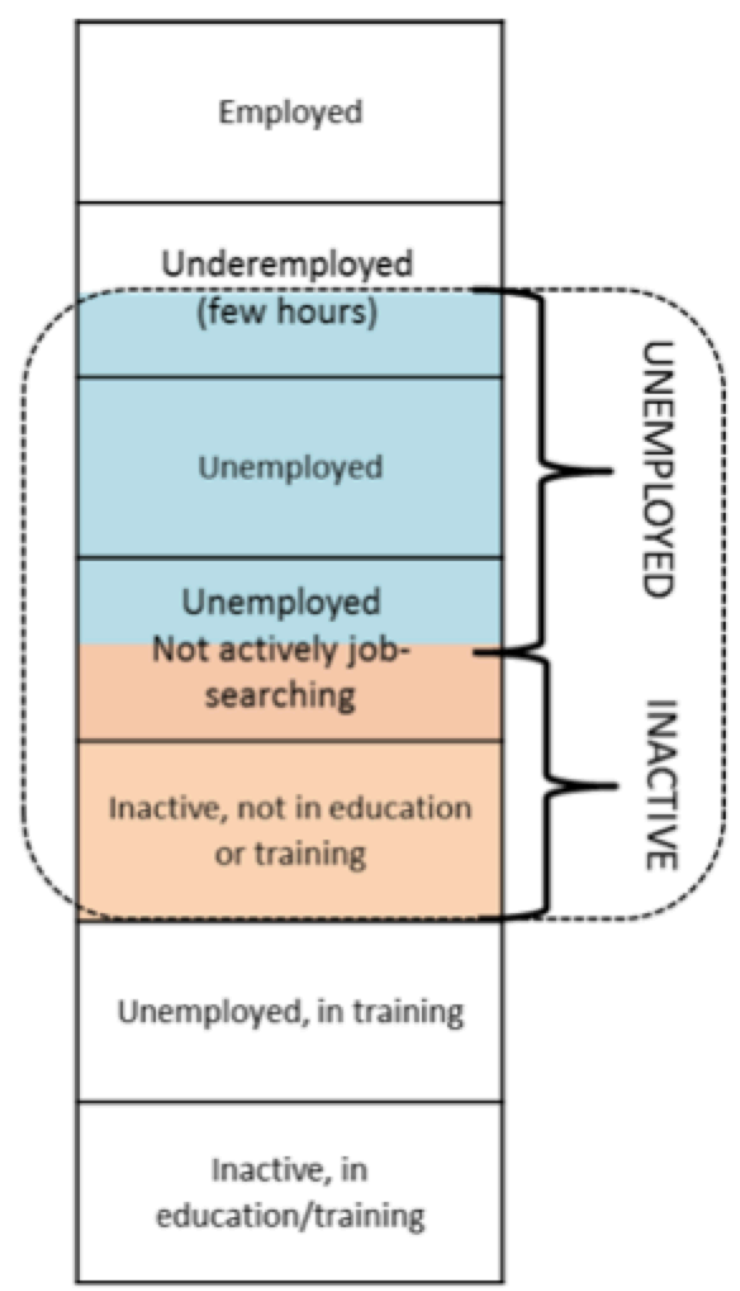


Figure 3: Individual trajectories by group type

Note: Blue=employed, Green=student, Red=NEET. (Y-axis: number of individuals; X-axis: months.)

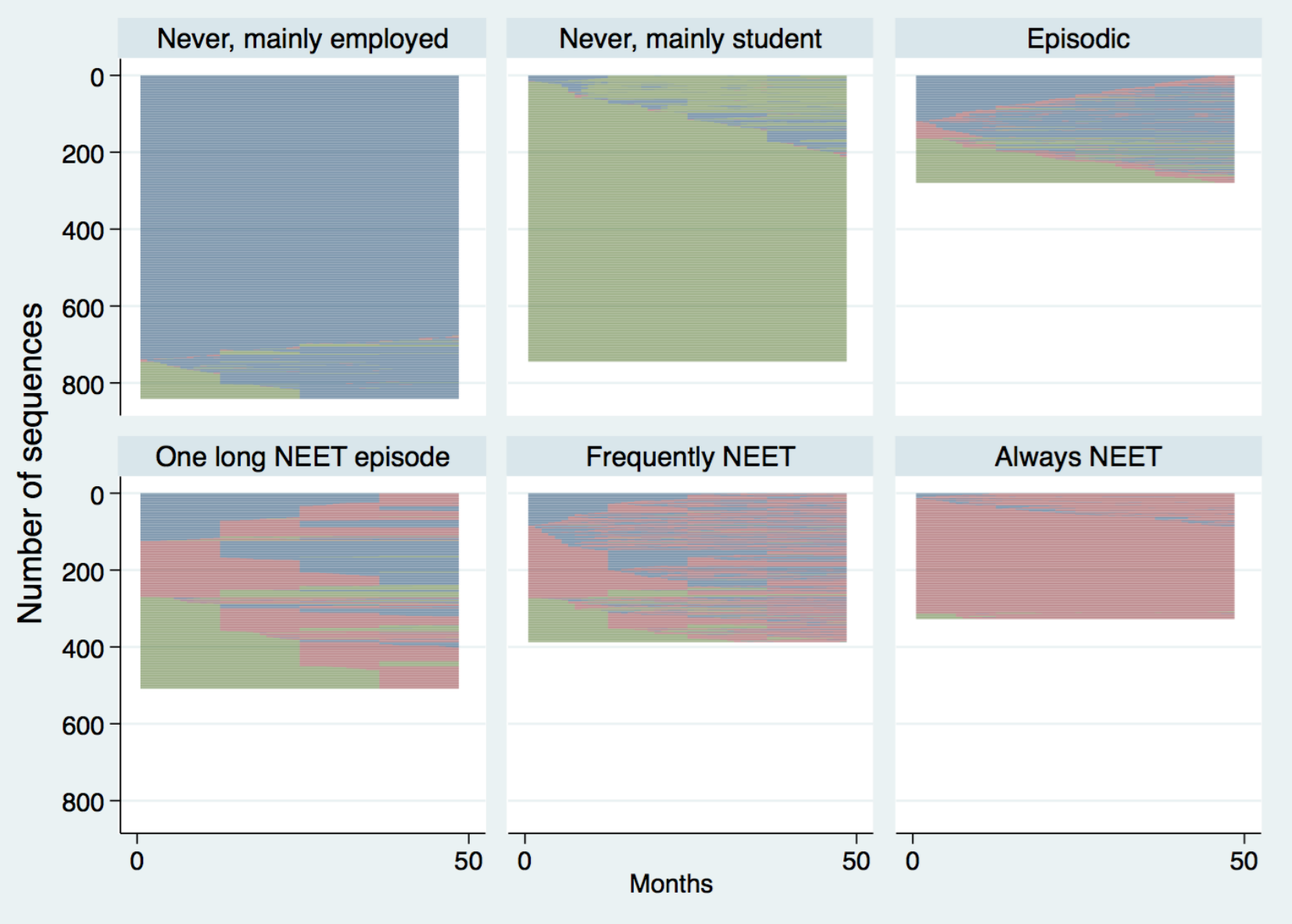


Figure 4: Predictive probability of being in each longitudinal group by gender and education at the first interview.

Controls: Age and area of residence. Predictive probabilities at the means of the other explanatory variables.
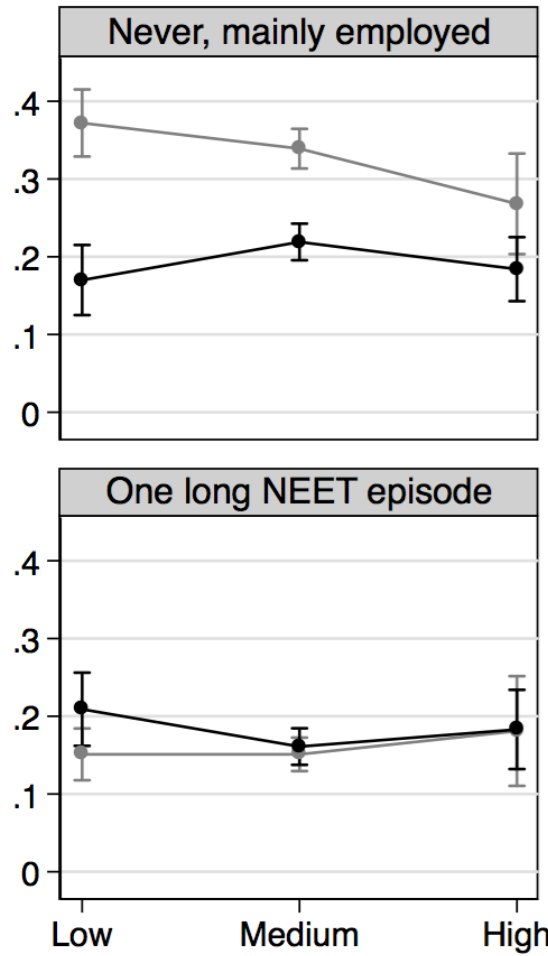

High Low
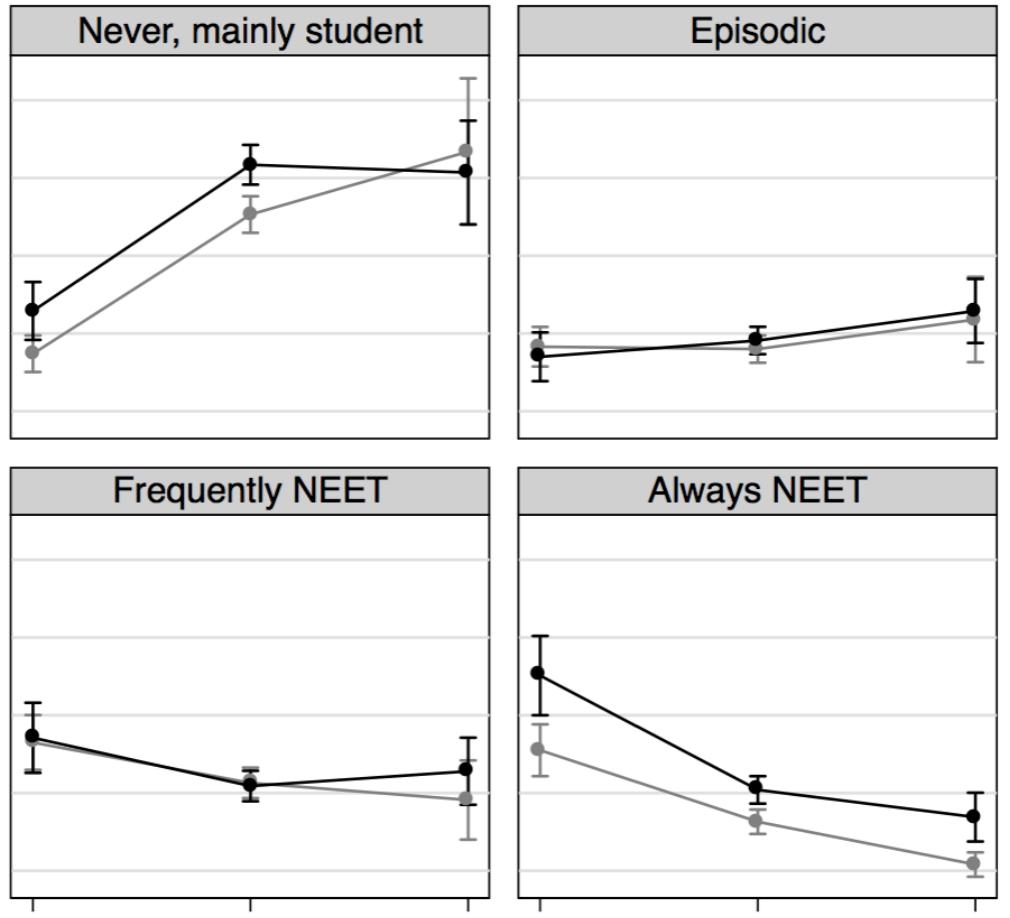

Medium

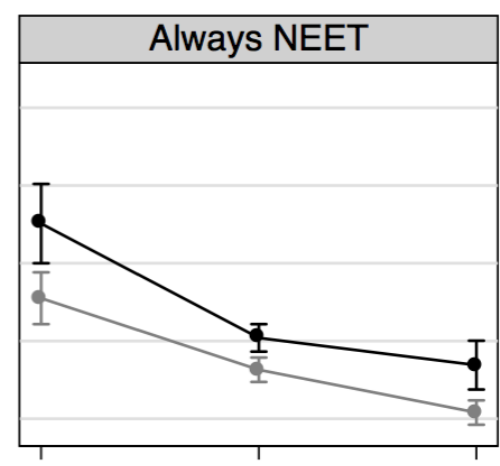

High Low

Medium

High

$$
\longmapsto \text { Male } \longmapsto \text { Female }
$$


Figure 5: Predictive probability of being in each longitudinal group by gender and age at the first interview.

Controls: Education and area of residence. Predictive probabilities at the means of the other explanatory variables.
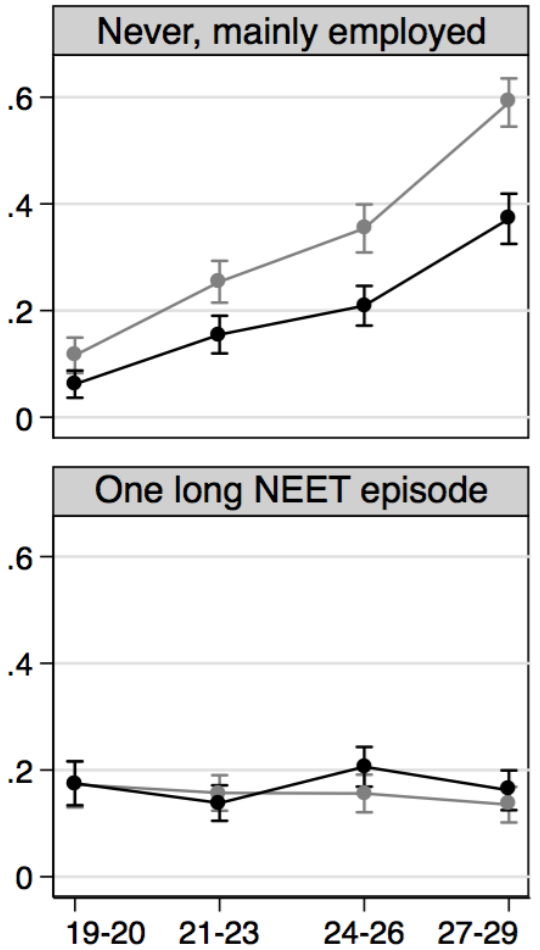
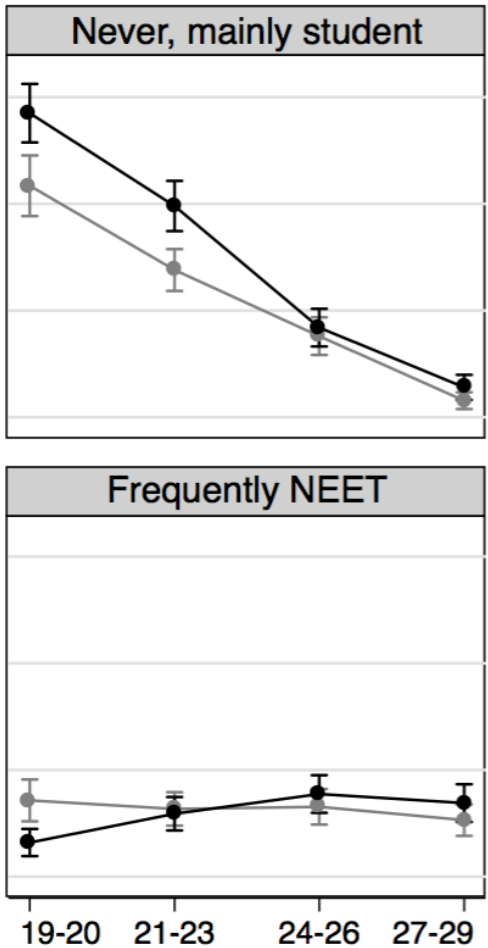
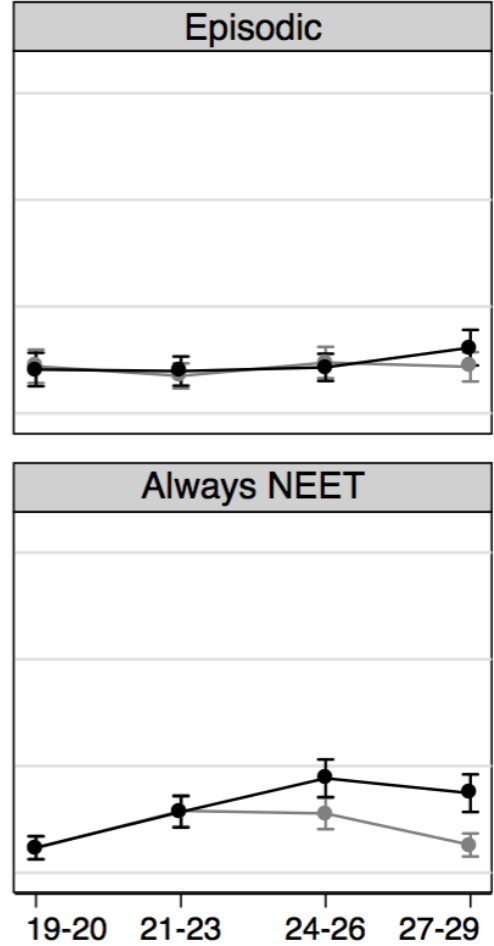

Male Female 
Figure 6: Individual trajectories of medium-long and always NEET by gender and age at first interview . Upper panel: age 19-23. Lower panel: age 24-29

Note: Blue=employed, Green=student, Red= NEET-Unemployed, Orange=NEET-Inactive

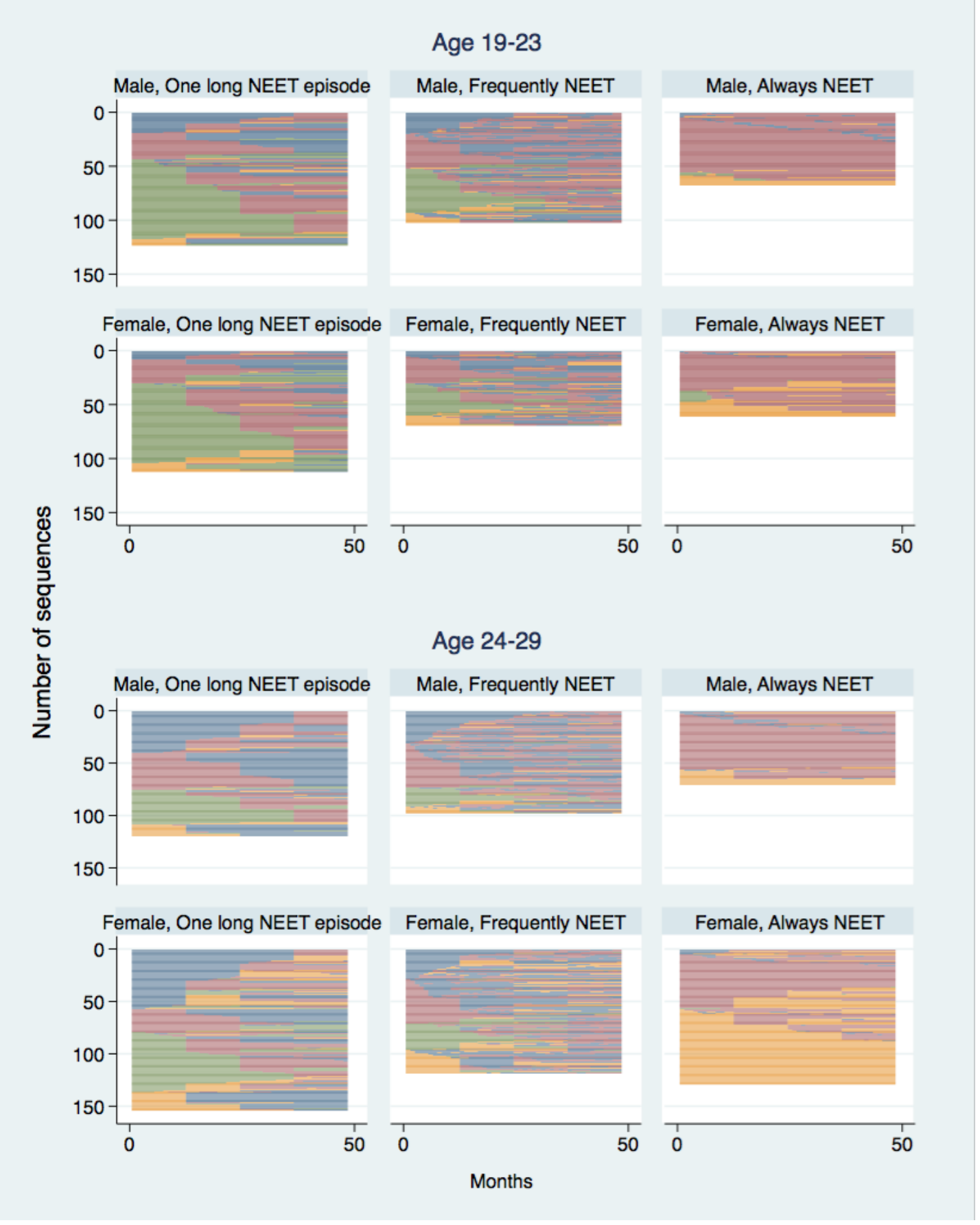




\section{Appendix. \\ Methodological notes on the probability of being long-term NEET}

We are used to think as long-term persistency in a state to have by definition a lower probability than that of occupying the state for one time unit. For example, the long-term poverty rate, defined as being in poverty for three consecutive years is smaller than the probability $p$ of being poor in one reference year.

In this paper, we have defined long-term NEETs as those observed being in the NEET state for at least 12 months out of 48. If $p$ is the NEET prevalence in a specific month, under the assumption of independency over time (i.e. if all individuals were hit by the same risk of being NEET at each time unit) the number of months spent as NEET is a binomial random variable $X$ with $n=48$. The probability of being long-term NEET $\mathrm{P}(X>=12)$ can be larger than $p$ (Table A1). Instead, the probability of being NEET in all 48 months would be $\mathrm{P}(X=48)=p^{48}$, i.e. nearly 0 unless $p$ is almost 1 .

Table A1. Probabilities under the independence assumption

\begin{tabular}{|c|c|c|c|}
\hline$p$ & $\mathrm{P}(X>=12)$ & $\mathrm{P}(X>=37)$ & $\mathrm{P}(X=48)$ \\
\hline 0.1 & 0.0022 & 0 & 0 \\
\hline 0.2 & 0.24 & 0 & 0 \\
\hline 0.3 & 0.82 & 0 & 0 \\
\hline 0.5 & 0.9998 & 0.0004 & 0 \\
\hline 0.9 & 1 & 0.9993 & 0.0064 \\
\hline
\end{tabular}

On the opposite side, we have the probability under the assumption of perfect dependency over time: those who are NEET will always be NEET, and those who are not will never be NEET. In this case, the probability of being long-term NEET, however defined, would be $p$ for some individuals and 0 for others.

To use this line of reasoning with our data, let us focus on the probability of being in the (almost) Always NEET group: $\mathrm{P}(X>=37)$. Taking $p=0.3$ (roughly the value observed at the cross-sectional level), under the independence assumption $\mathrm{P}(X>=37)=$ nearly 0 . Under the perfect dependency assumption, this probability is 1 for $30 \%$ of the population and 0 for the remaining $70 \%$, i.e. 0.3 in the overall population. We estimate a share of 0.106 , lying somewhere in between the values under independence $(0)$ and perfect dependence $(0.3)$. 